\title{
Study on Effective Cooperation of University-Admission Mode in Guangdong- Hong Kong-Macao Greater Bay Area
}

\author{
Ying Sun*
}

\author{
South China Normal University, Mainland China \\ ${ }^{*}$ Corresponding author. Email: $51249192 @ q q . c o m$
}

\begin{abstract}
According to the Outline of Guangdong-Hong Kong-Macao Greater Bay Area(GHMGBA)'s Development Plan, higher education should play an important role to accelerate the country's development. The author investigates the current admission mode of the all kinds of universities in GHMGBA and analyse their advantages and disadvantages. To conclude, innovation of joint admission, as well as the practice of open and diverse higher education admission systems in this area, can optimize the mechanism of the student cultivation. On the other hand, boosting the level of internationalization is also necessary to better the admission system and the paper takes the examples of the current co-ooperative admission mode between China, Israel, Arab states, Central and Eastern Europe to illustrate it. The new ideas of suggesting a Joint Admission Mode to satisfy the needs above and optimize the functions of universities in the GHMGBA development was not clearly raised in the past literature but based on the author's work and practice.
\end{abstract}

Keywords: Corporation, GHMGBA, University-Admission, the Belt and Road, Internationalization.

\section{THE IMPORTANCE OF CORPORATION AND INNOVATION IN UNIVERSITY-ADMISSION MODE}

Cross-border cooperative education in the GHMGBA is based on "one country, two systems" policy which is one of the characteristics of Chinese higher education and needs to obey the principles and rules of cross-border higher education. System has dual attributes, which is not only a special cultural capital, but also a tool of social stratification and flow, and even plays an important role in national construction.

The three famous Bay Areas are the San Francisco Bay Area, New York Bay Area and Tokyo Bay Area. They all have different and common characteristics: they all combine finance, science and Industry and the ultimate power is innovation. The source of innovation comes from the world-class university community. The table below shows the different indexes of GHMGBA comparing the famous three bay areas:

Table 1. The Basic Situation of the Economic, Social and Higher Education Development in Greater Bays in the world

\begin{tabular}{|l|l|l|l|l|}
\hline & GHMGBA & $\begin{array}{l}\text { San Francisco } \\
\text { Bay Area }\end{array}$ & $\begin{array}{l}\text { New York } \\
\text { Bay Area }\end{array}$ & $\begin{array}{l}\text { Tokyo Bay } \\
\text { Area }\end{array}$ \\
\hline GDP(Trillion US Dollars) & 1.5 & 0.82 & 1.83 & 1.86 \\
\hline Population(Ten Thousand Persons) & 7000 & 760 & 2340 & 3800 \\
\hline Number of Schools in Every Million people & 2.36 & 10.53 & 4.06 & 6.92 \\
\hline $\begin{array}{l}\text { Adoption of Higher Education in all } \\
\text { population(\%) }\end{array}$ & 17.47 & 46 & 42 & 36.7 \\
\hline Rank First 100 Universities in US News in 2018 & -- & 8 & 6 & 2 \\
\hline Rank 101-200 Universities in US News in 2018 & 4 & 1 & 2 & 1 \\
\hline Rank 201-500 Universities in US News in 2018 & 2 & -- & 5 & 2 \\
\hline
\end{tabular}


It is known that the advantages of GHMGBA is that has the biggest population and largest area among the other bay areas. And the total GDP is the equal of New York Bay Area and Tokyo Bay Area. Moreover, GHMGBA is the most economic actively and openly area in China. However, the GDP per capita is the lowest among the other bay areas and the higher education development is still improving. To be specific, the higher education levels of Guangdong, Hong Kong and Macao in the greater bay area all have their shortcomings: Hong Kong and Macao areas are limited in the source of students and the scale of education. Problems in Guangdong education: there are lack of high-level universities, gaps in structure of subjects and level of internationalization. There are no world rank First 100 Universities in the GHMGBA and the 4 universities which rank 101-200 in US News are all in Hong-Kong, which are Hong-Kong University, the Chinese University of Hong-Kong, The Hong Kong University of Science and Technology and City University of Hong Kong. Comparing with the other three bay areas, the higher education level is still far behind, which confines the developing speed of GHMGBA. Under the influence of "one country, two systems", the effective higher education integration mechanism has not been fully established. In the long run, to build a first-class bay area, the four cities of Guangzhou, Shenzhen, Macao and Hong Kong must have world-class or top-notch university clusters at the same time. Universities of various types and levels must also develop first-class or distinctive characteristics of different types. The cluster of high-level universities in GHMGBA should not only solve the problem of upgrading the level, but also solve the problem of interaction and development sharing. Admission of higher education is the entrance and an open window to the students, which is essential and basic in the procedure of higher education development. In the following paragraphs, the author will discuss the current situation and to explore an innovative mode of the higher education admission system in GHMGBA.

\section{ANALYSIS ON THE CURRENT REGULATIONS OF UNIVERSITY-ADMISSION MODE}

\subsection{The Ways for Hong-Kong and Macau Students to Study in Guangdong Universities}

\subsubsection{Undergraduate Admission Mode}

Generally speaking, there are four main modes for the Hong-Kong and Macau students to enter the listed Guangdong universities: early admission, joint exam admission, cooperative exam admission and independent exam admission. Firstly, early admission is only applicable to high school candidates who are recommended by the principle in their high school. It is also called School Principal Nomination Scheme (SPNS). Secondly, the joint examination admission: students can take the joint examination hold by the China Ministry of Education which is only for oversea Chinese, Hong-Kong, Macau and Taiwan high school graduates. The other way is the "four colleges joint exam admission": it's to examine the high school graduates' ability to attend the four institutes in Macau, which are University of Macau, Macao Polytechnic Institute, Tourism Institute and Macau University of Science and Technology, In Mainland China, there are 10 universities can accept the scores of the exam and three of they are in GHMGBA, which are Sun Yat-sen University, Jinan University and South China Normal University. Thirdly, the two universities cooperative exam: currently the Jinan University and Huaqiao University is holding the exam for Hong-Kong and Macau student admission. Fourthly, independent admission: so far only Sun Yet-sen University which is the top 1 university in Guangdong Province, has the qualification to organize the independent exams for Hong-Kong and Macau students. It is approved by the National Ministry of Education, whose requirements and contents of examination are decided by the university itself.

\subsubsection{Postgraduates Admission Mode}

In GHMGBA universities, there are two types of admission modes for Hong-Kong and Macau students to enter the Guangdong Universities. One is taking part in the exam for Hong-Kong, Macau and Taiwan People to study doctorate or master degree programs in Mainland China University, which is a unified examination. The other is to attend the National Graduate Exam which is the same to the mainland China students, but without the Politics subject. Although the "Application-Assessment" mode has been carried out in GHMGBA Universities to the mainland students for many years, it is not open to the Hong-Kong and Macau students, which is the main admission way of postgraduate in the worldwide.

\subsubsection{Advantages and Disadvantages of the Admission Modes}

Undergraduate admission modes focus on diversity and taking into account the cultural differences. But graduate student (doctorate and master degree) exam modes are both unified exams, and the requirements of the exam must be the same as for mainland China students. It is regardless of the different educational cultures and limited to attract Hong-Kong and Macau students to study in mainland universities. Therefore, the mode of enrolling graduates needs to be enlarged and developed more internationalization. 
Table 2. Five types of Admission Mode for Hong-Kong and Macau high school graduates to enter Mainland China University

\begin{tabular}{|l|l|l|l|}
\hline No. & $\begin{array}{l}\text { Admission Exam } \\
\text { name for short }\end{array}$ & $\begin{array}{l}\text { Number of } \\
\text { universities } \\
\text { countrywide } \\
\text { included }\end{array}$ & $\begin{array}{l}\text { Among } \\
\text { them in } \\
\text { the } \\
\text { GHMGBA }\end{array}$ \\
\hline 1 & $\begin{array}{l}\text { National Joint } \\
\text { Exam }\end{array}$ & 16 \\
\hline 2 & $\begin{array}{l}\text { Early Admission } \\
\text { School Principal } \\
\text { Nomination } \\
\text { Scheme (SPNS)] }\end{array}$ & $\begin{array}{l}\text { Holding "Four } \\
\text { college Joint } \\
\text { Exam" Scores to } \\
\text { enter the } \\
\text { mainland } \\
\text { university }\end{array}$ & 10 \\
\hline 4 & $\begin{array}{l}\text { Two Universities } \\
\text { Joint Exam(Jinan } \\
\text { University and } \\
\text { Huaqiao } \\
\text { University) }\end{array}$ & $\begin{array}{l}\text { Independent } \\
\text { Admission(Sun } \\
\text { Yet-sen } \\
\text { University) }\end{array}$ & 1 \\
\hline 5 & 1 & 1 \\
\hline
\end{tabular}

\subsection{The Ways for Guangdong Students to study in Hong-Kong and Macau Universities}

Hong-Kong and Macau Universities have highly internationalized admission modes and courses setting. For undergraduate admission, Hong-Kong and Macau universities adopt the scores of the China College Entrance Examination of the Guangdong students. Anyone who has better scores in the candidates can be accepted and his or her English exam scores should not be lower than 110 points or above at the same time.

For postgraduate admission, All the students including Hong-Kong and Macau residents, Mainland China and international students are based on the same admission brochure and requirements, while the English-speaking country students are not required the English ability qualifications. The admission modes are transparent and simply understanding. The majors are open to all students so they can choose freely by themselves.The Chinese University of Hong-Kong, Shenzhen is established in accordance with the Regulations on Chinese-foreign Cooperation in Running Schools upon approval of the Ministry of Education. It inherits the educational philosophy and academic systems of The Chinese University of Hong Kong. It is not a campus of the Chinese University of Hong-Kong in Shenzhen City but an independent Chinese-foreign cooperation university registered in Mainland China.
Because of the uniqueness of the university, it only have two admission ways to undergraduates for mainland China students: one is Comprehensive Evaluation Admission and the other is Early Admission in Foreign Language Major. The range is limited and narrow as far.

\subsection{The Admission Mode of Chinese-Foreign Cooperation University}

There are several Chinese-Foreign cooperation universities in GHMGBA. The author will take the Beijing Normal University-Hong Kong Baptist University United International College, Shenzhen MSU-BIT University and Guangdong Technion-Israel Institute of Technology (GTIIT) for examples. Beijing Normal University-Hong Kong Baptist University United International College(short for UIC), which is the cooperation between Mainland China and Hong Kong under the higher education regulations in both sides. And the other is Shenzhen MSU-BIT University, a non-profit higher educational institution, jointly established by Shenzhen Government, Lomonosov Moscow State University and Beijing Institute of Technology. The undergraduate admission mode of UIC has all the ways for Hong-Kong and Macau students mentioned above, and it has its extra preference to them which is unique in the GHMGBA, as well as in Mainland China. Firstly, for Hong-Kong applicants who are associate degree / higher diploma holders, they can apply for Year 2 or Year 3 entry. Secondly, for Macau applicants holding International qualifications can apply for Year 1 entry. The international qualifications include American pattern, British pattern and Australia pattern. Under every pattern, they have a detailed score requirements. Considering the graduate admission mode, the UIC highly matches the international mode that all the doctorate and master degree applications adopt the "Application-Assessment" mode and no unified examinations are required.

Whilst, Shenzhen MSU-BIT University is the corporation of the Chinese and Russian governments, so it does not include Hong-Kong and Macau people admission policy but it has a opener way to students in Central and Eastern Europe. The applicants are divided into Russian Nationality and other country's nationality holders. The two categories of applicants are selected according to different evaluation principles, and the enrollment plan for each major is set according to the two applicant categories. Guangdong Technion-Israel Institute of Technology (GTIIT) is established by Shantou University (STU) and the Technion - Israel Institute of Technology (short for the Technion). The Technion is a world-leading institute of higher education with three Nobel laureates and remains top 50 in global research-based university rankings which is located in Israel, the important scientific and cultural center in the Middle East area. GTIIT considered to be the 
combination of GHMGBA and Israel. Its specialty in innovative research, environmental conservation, and social prosperity will benefit both China and Israel. Its admission plan is divided into three parts: Mainland China students, Hong-Kong, Macau students and international students. There are no special policy towards Israeli students and they are regarded as the same requirements as other international students. The admission mode in GTIIT is still developing and choices of majors are too few. Although it needs time and effort to achieve its goals, it's the new attempt to run it as a cultural bridge between China and Israel.

\subsection{Deficiencies in the Current Admission Mode}

Nowadays there are 157 universities, a number of influential scientific research institutions, high-tech enterprises and national major scientific projects in the GHMGBA. But the cooperation and joint admission is still insufficient and every school just focuses on their own development and lack of exchange and mutual learning. That makes the higher education development of the three places highly unbalanced and insufficient, as well as the internationalization in this area. The kind of joint admission mode is essential to be carried out and the government should take the responsibility to strengthen the top-level design of cooperation and development between different universities, in order to promote the strengths of higher education as an engine to serve the whole society in these areas.

The regional flow of the university students among Hong Kong, Macau and Mainland China is a kind of flow in a sovereign state in different administrative regions, a newly built and special development mode in the educational globalization. it's the first new mode of cooperation even in the worldwide which should require a deeper and higher corporation. Meanwhile, internationalization in Guangdong universities is still low that cannot match the development of the society and economics in the GHMGBA in the upcoming years.

\section{EXPLORING THE INNOVATIVE MODES OF GHMGBA JOINT ADMISSION MODES}

\subsection{Joint Admission Enlarged in Arts and Sports}

Some subjects like music, dance, fine arts and sports are called "the mutual global languages", which have little political attributes and no national boundary. In these majors, scholars are easier to get common standards and understandings, and the universities in the GHMGBA should have a separate and independent admission plan to attract arts and sports students from the other sides. For example, develop the joint admission mode among the Guangzhou Academy of Fine Arts, Xinghai Conservatory of Music in Guangdong and The Hong Kong Academy for Performing Arts, which all focus on students' arts cultivation. They can establish the joint cultivation courses and program to enlarge the academic exchange between arts colleges in two systems. The similar joint development mode can occur in arts or sports faculty in universities. Last year, the Department of Cultural and Creative Arts in The Education University of Hong-Kong and the Music School of South China Normal University signed the cooperation memorandum based on the Development Plan For Guangdong-Hong Kong-Macao Greater Bay Area (2019) to Promoting the strategic talent development program. The same mode can be carried out in sports majors.

\subsection{Special Admission Project for Joint Training of Postgraduates}

Following the model of Guangdong Province Education Department's joint training base construction, the special admission project for enrolling postgraduate students joint training in Guangdong, Hong Kong and Macao universities is to be formulated.

One way is that cooperative universities recommend outstanding undergraduate graduates to study for master or doctorate degree in the other side's characteristic and preponderant discipline.

The other way is that universities in Hong Kong and Macao are encouraged to develop the joint admission mode with the enterprises in Mainland China in the GHMGBA, to cultivate the professional degree postgraduate who can meet the new requirements of the industry development. What's more, the major of Law, Taxation, Intellectual property and related disciplines are encouraged to be strengthened, which can cultivate outstanding postgraduate talents who are familiar with international and bay area rules, so as to raise the level of professional development to meet the international requirements.

\subsection{Launching and Enlarging the Special Needs and Characteristic Majors}

\subsubsection{Launching the New majors}

According to The Development Plan for Higher Education in Guangdong-Hong Kong-Macao Greater Bay Area (Draft by the Department of Education in Guangdong Province), Guangdong Province are possibly admitted to independently set up the majors out of the National Directory for urgent need of the Greater Bay Area, reported to the National Ministry of Education for the record. The University of Macau (UM) has this kind of actions last year: in the 2019/2020 academic year the UM will launch five new bachelor's 
degree programmes in education, science, precision medicine, big data and business intelligence respectively, to nurture high-calibre professionals who can fulfill the different needs of Macao and contribute to the development of the Greater Bay Area with the latest technologies.

In addition, Macao is supported to be built as the Chinese-Portuguese bilingual training centre and a GHMGBA tourism education and training base. New majors related to the bilingual training and cross-border tourism are brought out and in great need. The author suggests the vocational and technical colleges in both Macau and Guangdong should launch some new majors to suit the specialty of GHMGBA development.

\subsubsection{Enlarging the Existing Majors greatly in need}

Universities in Guangdong should enlarge the existing urgent needed majors like cross-border, Multilanguage law, insurance and commerce etc.. It is also encouraged to set the independent admission program and early admission program on these areas to attract suitable undergraduate and postgraduate students who are willing to serve in the GHMGBA after graduation.
In the study of the first five majors in the Macau universities students studied in, it is showed that commerce and management, tourism, law and languish are the most popular subjects, which also match the GHMGBA development. Therefore, whether in Guangdong or in Macau and Hong-Kong, the existing majors related to the above should be strongly considered. In addition, Scholarship and assistantship should extend to more Guangdong students who are eager to study in Hong-Kong and Macau. Encourage Excellent Hong-Kong and Macau students in these majors to the short-term visiting in the GHMGBA universities and establish the sound mutual recognition of credits are the positive ways to enlarge the admission range. University of Macau has set a good example of it, and it is called" Scholarship for Students From Guangdong Greater Bay Area"(tuition fee waived). The scholarship is awarded to the GHMGBA students, including from Guangzhou, Zhuhai, Zhongshan, Shenzhen, Dongguan, Jiangmen, Foshan, Zhaoqing and Huizhou) with excellent scores of the College Entrance Examination. In addition to exempting tuition fee and residential fee for the first year, scholarship recipients are also given preference in admission to the Honors College.

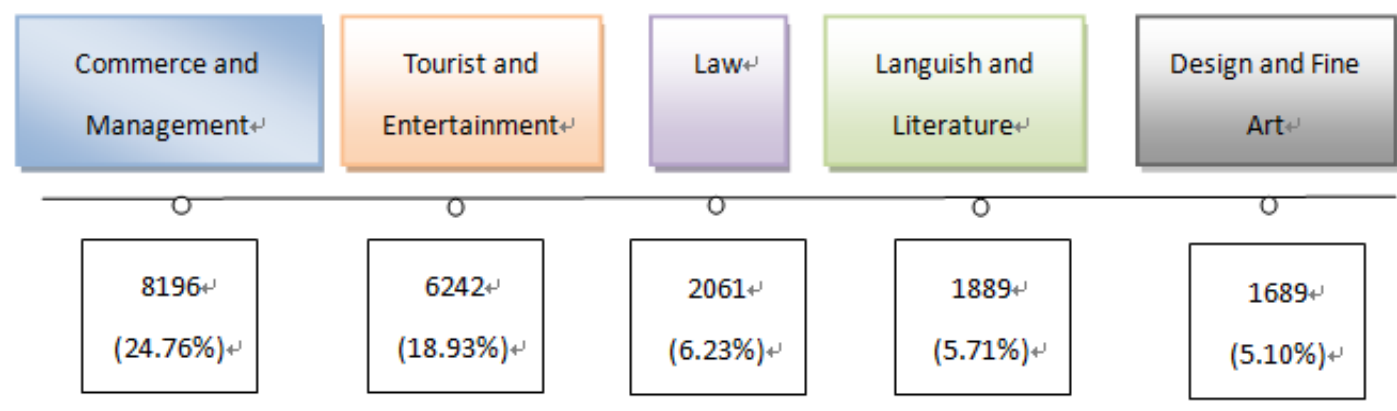

Figure 1 Year 2017/2018 The First 5 Major in Macau Universities

Source: Macau Higher Education Bureau

\subsection{Promoting the International Level of Admission System}

Now the international level in Guangdong higher education is comparatively low and "One Belt, One Road" policy brings opportunities for the development of disciplines in Guangdong universities, which can be regulated in terms of introducing advanced and mature disciplines from other countries, while these regulations are blank or insufficient.

The GHMGBA universities should corporate with the higher education institutions along the "Belt and Road "line to establish the joint training program and platform. For example, Guangdong Technion-Israel Institute of Technology (GTIIT) cooperates with Israel
Institute of Technology to set joint training plan on engineering, science and life science to allow students to study in both sides. The GTIIT should also need to provide independent admission plans for Israeli students, to enlarge the impact of the school in both China and Israel. In terms of Chinese-foreign higher education cooperation, China has set up oversea branches in Singapore, Laos, Thailand and Malaysia. There are more than 100 cooperative school-running projects between China and ASEAN, mainly universities. There are 2+2, $3+1$ undergraduate programs, and 2+1 Master program. However, China-Arab admission cooperation in higher education is limited to Confucius Institutes and Confucius Halls, which has not been widely extended. Refer to China-Central Europe corporation, only Poland has eight corporate projects. Moreover, the above cooperation projects are mainly about language 
cooperation, which cannot bring the advantages of university disciplines into full play. All these show that the establishment of educational cooperation between China and Arab league countries and central European countries are not ideal. The dialogue and coordination mechanism between regional systems is not enough, which leads to the small overall cooperation system between China and Arab states, Central and Eastern Europe. In the future, it is suggested to further maintain the existing culture output like Confucius Institutes, language schools, whereas keep enhancing deep cooperation in disciplines and subjects, encouraging the schools with similar disciplines to alliance.

\section{CONCLUSION AND SUGGESTION}

Despite the three main different education systems in GHMGBA, there are conflicts and more are opportunities in the field of corporations. The educational inter-regional specialty in this area should be taking into account greatly which can be differentiated from international and domestic corporation.

The frame of joint admission mode is to be established containing these elements: opener mind of admission standards in some disciplines especially on art and sports; To fully play the advantages of universities in Hong Kong and Macao in terms of education system and innovative resources, the paper suggest a frame of joint admission mode as Figure 2.Higher education institutions in Hong Kong and Macao should cooperate with universities in GHMGBA in terms of admission and joint training in the form of "school + school" or "school + enterprise", in order to set up a group of high quality projects. Actively respond to the "Belt and Road" initiative, the universities in the Greater Bay Area should serve the "Belt and Road" countries under the government support, focus on training non-general language talents, foreign law talents, local engineering techniques talents and international trading talents et cetera.

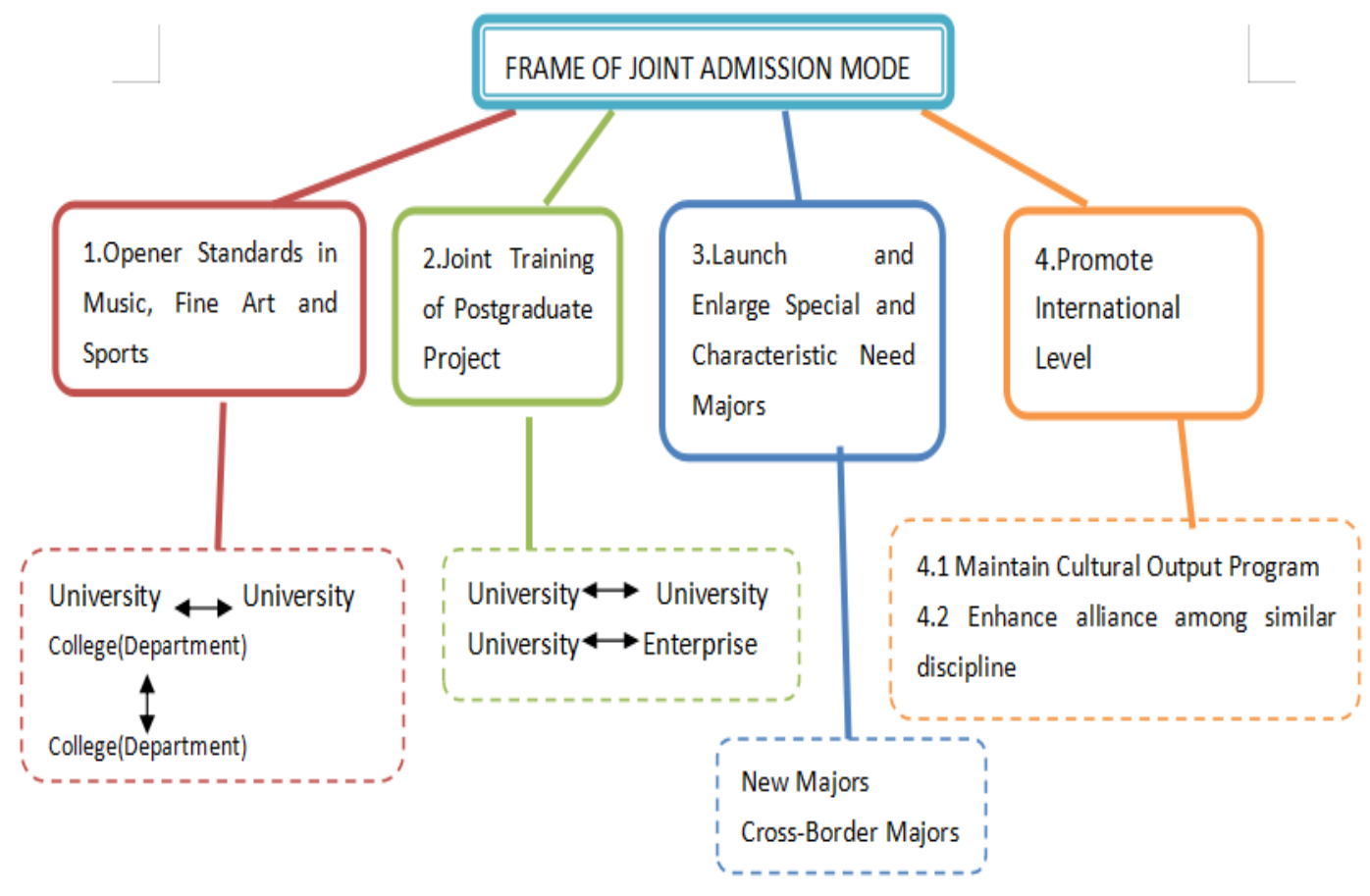

Figure 2. The Frame of Joint Admission Mode

Figure 2 The Frame of Joint Admission Mode

\section{REFERENCES}

[1] Journal article Yanling LIU, System Supply of "One Belt, One Road" Higher Education Exchange And Cooperation, Published in Jiangxi Social Sciences.

[2] Journal article Changqing XU, Xiaozhong LU, Guangdong-Hong Kong-Macao Greater Bay Higher Education Integration and Development:
Idea, Reality and System Isomorphism. Published in Journal of Higher Education, January 2019.

[3] Online document Hong Kong Annual Digest of Statistics. 2017 Edition. Section 12 Education [EB/OL].[2018-06-15].<https://cdcf.ugc.edu.hk/cdc f/statSiteIndex.action>.

[4] Journal article Xuelin XIAN, Dongping AN: Study on the current situation and cooperation pattern of higher education in Guangdong-Hong Kong-Macao 
Greater Bay, published in Journal of Shenzhen Institute of Information Technology, Vol.15 No.4 Dec. 2017.

[5] Statistics from Macau Higher Education Bureau website:

https://www.dses.gov.mo/queryinfo/entrance, 2020/6/8. 